\title{
LOS SEÑORES DE YAXCHILÁN. UN EJEMPLO DE FELINIZACIÓN DE LOS GOBERNANTES MAYAS*
}

\author{
Laura E. Sotelo Santos \\ Ma. del Carmen Valverde Valdés \\ CEM, IIF, UNAM
}

Entre las diversas representaciones de los soberanos de Yaxchilán, destacan aquellas en que aparecen éstos con ciertos elementos que se asocian con el jaguar (Panthera onca). Aunque la relación del felino con el gobernante no es exclusiva de este sitio del Usumacinta, ya que está presente no sólo en otros puntos del área maya, sino en toda Mesoamérica (región que se ubica dentro del área de distribucion original del animal), hemos elegido el caso concreto de Yaxchilán como un ejemplo para acercarnos al estudio de algunas ideas y prácticas de los gobernantes, que los vinculan estrechamente con el jaguar.

Partiendo de la idea de que ciertas bases del pensamiento maya de la época Clásica perduran hasta el Posclásico, y en algunos casos más allá de la Conquista, hemos decidido hacer un análisis comparativo entre las representaciones en piedra de esta urbe, y la tradición escrita en lengua quiché conservada principalmente en el Popol Vuh.

\footnotetext{
- Asesoría científica: Biol. Arcadio Ojeda Capella

Agradecemos al Dr. Arturo Romano toda la información sobre deformación craneana entre los mayas y el apoyo brindado para la realización de este trabajo.
} 
Es importante hacer mención que el presente trabajo es un primer acercamiento al tema, por lo que únicamente se apuntarán algunas ideas; estamos concientes de que éstas ameritarán futuras y más profundas investigaciones.

A través de la epigrafia conocemos el nombre glifico del fundador de la dinastía de Yaxchilán, o al menos al que los mandatarios posteriores consideraron como tal. Estamos haciendo referencia en este caso a "Progenitor Jaguar", quien según las inscripciones gobemo el sitio hacia el 359 d.C., lo que nos podría indicar el origen mítico del linaje, ya que los primeros registros escritos datan del afio 514 d.C. (estela 27). Asf, seguramente cuando empezó el gran auge de Yaxchilán, se registró el pasado en función de la tradición oral, uniendo de manera indisoluble el mito y la historia.

Entre los diez primeros gobemantes de Yaxchilán, que corresponden al Clásico temprano, encontramos que el glifo de cinco de ellos incluyen precisamente al jaguar en su nombre. Es así que, según la interpretación que se ha hecho de las inscripciones, tenemos a Progenitor Jaguar, Deidad Jaguar, Pajaro Jaguar I, Pajaro Jaguar II y Jaguar Ojo Anudado. ${ }^{1}$ (Fig. 1)

A partir del año 629 d.C., cuando se inicia la época de esplendor de la ciudad, el jaguar siempre aparecerá en los nombres de los gobemantes. Con Pájaro Jaguar III se inicia el desarrollo propiamente dicho de la urbe y, junto con él, una tradición historiografica que nos permite reconstruir parte de la historia politica del sitio. Quien marca el inicio del perfodo de mayor apogeo de Yaxchilán es Escudo Jaguar II (752 d.C), y a pesar de sólo haber gobemado durante dieciseis affos, emprendio una labor sin precedente en Yaxchilán; a su gobiemo corresponde más de la mitad de la escultura del sitio. Su hijo, Pájaro Jaguar IV (771 d.C.), quien heredó el título del abuelo, cierra la época del gran esplendor de la ciudad y la dinastía de los jaguares. Después de este jerarca, úni-

${ }^{1}$ Sotelo, Yaxchilán, p. 59. En prensa. 

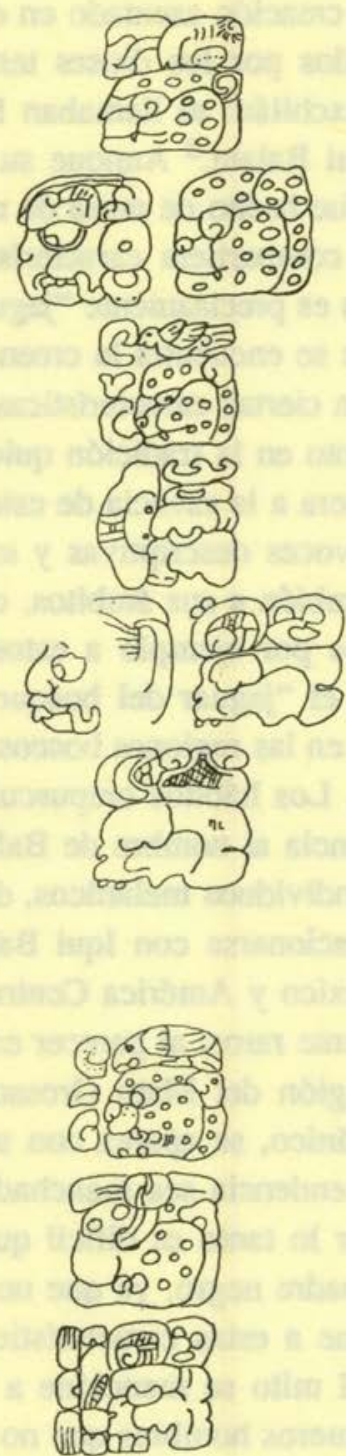

1. Nombres jeroglificos de los primeros gobernantes de Yaxchilán.

Estudios de Cultura Maya. Vol. XIX, 1992

Instituto de Investigaciones Filológicas/

Centro de Estudios Mayas, UNAM

ISSN 0185-2574 
camente quedó registrado el nombre del último de los grandes soberanos: Mahk'ina Cráneo III (808 d.C.). (Fig. 2).

Según el mito de la creación asentado en el Popol Vuh, los primeros hombres formados por los dioses tenfan el apelativo "jaguar" igual que en Yaxchilán: se llamaban Balam Quitzé, Balam Akab, Majucutah e Iqui Balam. ${ }^{2}$ Aunque su cuerpo, igual que el de todos los hombres fue hecho de masa de maiz, es probable que su naturaleza anímica compartiera características felinas, pues el nombre de tres de ellos es precisamente "jaguar".

En diversas latitudes se encuentra la creencia de que el nombre de un individuo alude a ciertas características de su propia naturaleza; es posible que tanto en la tradición quiché como en Yaxchilán, el apelativo se refiera a la esencia de estos primeros hombres, es decir, tal vez sean voces descriptivas y su nombre aludirfa no sólo al animal, sino también a sus ámbitos, costumbres y características físicas. Veamos por ejemplo a estos hombres del Popol Vuh: Balam Quitzé es el "jaguar del bosque", y este depredador habita preferentemente en las regiones boscosas, es decir, cubiertas por un estrato arbóreo. Los hábitos crepusculares y noctumos del carnívoro harían referencia al nombre de Balam Akab, "jaguar de la noche", y aquellos individuos melánicos, de pelaje negro o pardo oscuro, podrían relacionarse con Iqui Balam (Eke Balam), el "jaguar negro". En México y América Central, los jaguares melánicos son extremadamente raros; al parecer estas fases oscuras son más comunes en la región del Mato Grosso en Brasil. Por otro lado, si un jaguar melánico, se aparea con un manchado, lo más factible es que su descendencia sea manchada —el melanismo es un gene recesivo- por lo tanto es difícil que a sus cachorros se les identifique con el padre negro, ya que no presentan su mismo fenotipo. Es posible que a estas características biologicas del jaguar se deba que en el mito se mencione a Iqui Balam como el único de los cuatro primeros hombres que no dejo descendencia.

${ }^{2}$ Popol Vuh, p. 104. El significado de estos nombres ha sido analizado por Carmack en Evolución del reino quiché, p. 78. 

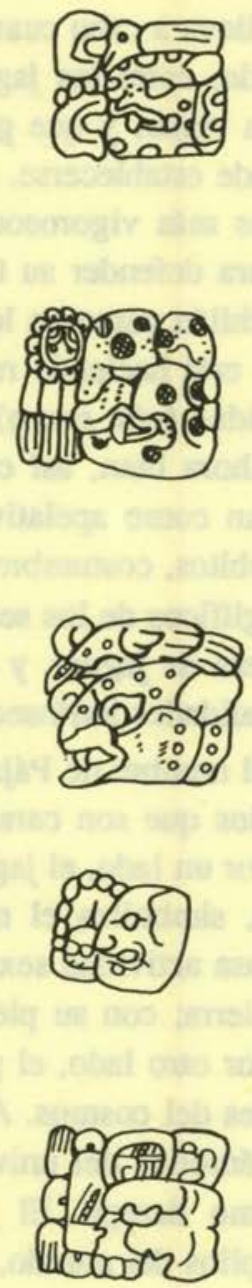

2. Nombres jeroglificos de los gobernantes de Yaxchilán del siglo VII al IX.

Estudios de Cultura Maya. Vol. XIX, 1992

Instituto de Investigaciones Filológicas/

Centro de Estudios Mayas, UNAM

ISSN 0185-2574

httn://www iifilologicas unam.mx/estculmava/ 
Mención aparte merece Mahucutah, nombre que según Carmak significa "uno que no permanece, viajero"3. Esto, si lo aplicamos al jaguar, se podria relacionar con el amplio territorio que tiene y defiende cada animal (sobre todo los machos), asi como los grandes desplazamientos que lleva a cabo cuando escasean los recursos alimenticios. Por otro lado, entre los jaguares existen individuos errantes que se dedican a viajar, y que generalmente son jovenes en busca de un lugar donde establecerse, o machos viejos que han sido expulsados por otros más vigorosos, y que ya no tienen la fuerza fisica necesaria para defender su territorio. Asi, podriamos pensar que tanto en Yaxchilán como en los nombres de los gobernantes del Popol Vuh, se esté haciendo referencia a las características esenciales del individuo (vid. supra) que en este caso, serfan evidentemente felinas. Ahora bien, así como en el texto quiché, los grandes seffores llevan como apelativo la voz Balam y otras que se referirfan a los ámbitos, costumbres y características físicas del animal, los nombres glfficos de los sefiores de Yaxchilán están compuestos por una cabeza de jaguar, y otros signos que se pueden relacionar con las cualidades intrinsecas del gobemante.

En el caso del glifo del nombre de Pajaro Jaguar, se reúnen dos elementos complementarios que son características fundamentales de los grandes seffores. Por un lado, el jaguar, como lo han seffalado varios investigadores, simboliza el mundo subterráneo, y es probable que por su intensa actividad sexual ${ }^{4}$ se asocie con la fertilidad inagotable de la tierra; con su piel se representa el manto estrellado de la noche. Por otro lado, el pajaro se vincula con los aspectos diurnos y celestes del cosmos. Asi, el gobemante integra en su nombre estos dos ámbitos del universo que son opuestos y complementarios al mismo tiempo. El tener acceso, simb6licamente, a sectores tan amplios del mundo, aludiría a una capacidad rectora sobre el mismo.

${ }^{3}$ Carmack, Ibid.

4 Ibarra y Ojeda, Estudios sobre patrones básicos del comportamiento del jaguar (Panthera onca) en cautiverio, p. 1. 
Cuando en el Popol Vuh se habla de Gucumatz (literalmente "serpiente emplumada"), gobemante del linaje quiche, descendiente de uno de los cuatro primeros hombres, se dice que era un "rey" prodigioso, que su naturaleza era maravillosa, y que, entre otras cosas, había días en que se convertía en "tigre".

Verdaderamente, Gucumatz era un rey prodigioso. Siete días subía al cielo y siete días caminaba para descender a Xibalbá; siete días se convertía en culebra y verdaderamente se volvía serpiente; siete días se convertía en águila, siete días se convertía en tigre: verdaderamente su apariencia era de águila y de tigre. ${ }^{5}$

Todo esto lo hacía "solamente para que hubiera un medio de dominar a todos los pueblos, como una demostración que sólo uno era llamado a ser el jefe de los pueblos". ${ }^{6}$

Esta supremacía muchas veces se consegura a través de una actividad fundamental: la guerra. Según el Popol Vuh, entre las obligaciones de los hombres del linaje estaba el obtener prisioneros para el sacrificio a los dioses.

A partir del momento de la creación de los hombres se establece la relación contractual entre éstos y los dioses, es decir, los gobernantes tienen la obligación de proveer el sustento a sus creadores quienes a su vez los ayudarán a conservar su poderfo. Asf, Tohil, Avilix y Hacavitz fueron "alimentados" con la sangre que los quichés obtenían básicamente al hacer la guerra y tomar prisioneros de otros grupos.

Y entonces habló Tohil; sólo por un prodigio les dió sus consejos a los sacerdotes y sacrificadores. Y ellos (los dioses) hablaron entonces y dijeron: "Verdaderamente aquí serán nuestras montañas y nuestros valles. Nosotros somos vuestros; grandes serán nuestra gloria y nuestra descendencia por obra de todos los hombres. Vuestras son todas las tribus y nosotros vuestos compañeros. Ciudad vuestra ciudad y nosotros os daremos vuestra instrucción...

${ }^{5}$ Popol Vuh, p. 149-150. Es evidente que cuando el texto hace referencia a leones y tigres, se trata de pumas y jaguares respectivamente.

${ }^{6}$ Ibid. El subrayado es nuestro. 
Grande será vuestra condición; dominaréis a todas las tribus; traeréis su sangre y su sustancia ante nosotros, y los que vengan a abrazarnos, nuestros serán también", dijeron entonces Tohil, Avilix y Hacavitz. ${ }^{7}$

Es muy probable que ésta sea una tradición que se remonte hasta el Clásico, y que una de las finalidades de las contiendas emprendidas por los gobernantes de Yaxchilán haya sido no s6́lo ensanchar sus dominios y áreas de influencia, sino tambien obtener prisioneros para ofrendar su sangre a la divinidad. Cabe hacer la aclaración, que en la escultura del Usumacinta siempre se encuentran representaciones de prisioneros vivos, a quienes seguramente se les sacrifico después, sin embargo no hay ninguna imagen que nos permita afirmar esto último. Pero, independientemente del destino final de los prisioneros, el hecho de la guerra misma está presente en estelas, dinteles, etc. y aún en los nombres de los mandatarios de Yaxchilán. En el de Escudo Jaguar, al elemento felino se le añade uno bélico, y dada la importancia de la guerra entre los pueblos prehispánicos, no es de extrañar que un objeto asociado con esta actividad se haya incluido en el glifo nominal del mandatario.

En el Popol Vuh hay referencias a las actividades bélicas de los cuatro primeros hombres que nos pueden arrojar alguna luz acerca del sentido de capturar prisioneros y el destino final de éstos.

He aquí como comenzo el robo de los hombres de las tribus por Balam Quitzé, Balam Acab, Mahucutah e Iqui Balam.

Luego vino la matanza de las tribus. Cogían a uno solo cuando iba caminando, o a dos cuando iban caminando, y no se sabía cuando los cogían, y en seguida los iban a sacrificar ante Tohil y Avilix. Después regaban la sangre en el camino. Y decían las tribus: "El tigre se los comio." Y lo decían así porque eran pisadas de tigre las huellas que dejaban, aunque ellos no se mostraban. ${ }^{8}$

${ }^{7}$ Ibid., p. 125-126. El subrayado es nuestro.

${ }^{8}$ Ibid., p. 128. 
El texto destaca, no solo la suerte que corrian los hombres de las demás tribus en manos de los quichés, sino también la forma en que estos cuatro primeros hombres "cazaban" a sus víctimas para el sacrificio. En este sentido, su comportamiento nos hace pensar en el jaguar. En primera instancia vemos que los hombres eran atrapados de uno en uno o por parejas, pero nunca en grupo. Esto es característico de la técnica de cacería del felino: elige a su presa (no a un grupo) y la acecha, a veces por largo tiempo, hasta que cae sobre ella. Normalmente el blanco del ataque es la nuca de la víctima, y en ocasiones, ya sea por medio de un zarpazo o, generalmente, de una mordida, desprende la cabeza del resto de su cuerpo. La fuerza que tiene en sus poderosas fauces y en sus vigorosas garras le da esta posibilidad. Por otro lado, lo que al animal le interesa para alimentarse son las partes blandas del cuerpo, por lo que suele abandonar la cabeza de la presa y arrastra, a veces por largos trayectos, el resto del cuerpo hasta un sitio tranquilo donde lo devora; puede ser sobre las ramas de algún árbol. Esto explicaría porqué las tribus dicen que estos cuatro primeros hombres "regaban la sangre en el camino y ponfan la cabeza por separado en el camino".

Vemos entonces, que estos hombres no solo tienen el apelativo Balam, sino que muchas de sus actitudes los relacionarian con el animal, y nos harian pensar en esta naturaleza felina a que hicimos referencia, y que se confirmaría cuando los pueblos comentan que fue el "tigre" el que se los comio, porque además, las huellas que dejaban "eran como pisadas de tigre". Generalmente los únicos rastros que deja el jaguar en sus senderos son, además de señales olfativas, precisamente sus huellas. Más adelante, el texto del Popol Vuh reitera este fenómeno de las "pisadas" diciendo:

Entonces celebraron consejo entre ellos. A continuación comenzaron a seguir las huellas de los sacerdotes y sacrificadores, pero éstas no eran claras. S6́lo eran pisadas de fieras, pisadas de tigre lo que veían, pero las huellas no eran claras. No estaban claras las 
primeras huellas, pues estaban invertidas, como hechas para que se perdieran, y no estaba claro su camino. ${ }^{9}$

Sobre la conducta del jaguar en libertad hay pocos estudios, sin embargo, hay un sin fin de reportes de cazadores y naturalistas ${ }^{10}$ que indican la enorme dificultad que implica detectar en la selva a uno de estos animales, aún teniendo sus huellas. Incluso mencionan que después de varios días, el individuo que creen haber seguido, en realidad los ha estado siguiendo a ellos. ${ }^{11}$ Por otro lado, el hecho de que las huellas aparezcan invertidas, se debe a que el animal, para desplazarse hacia el sitio donde va a devorar a su presa, sostiene a ésta con el hocico y la arrastra caminando hacia atrás. Existen otros comportamientos del félido reflejados en los hombres quichés. Veamos por ejemplo el siguiente pasaje del $\mathrm{Po}$ pol Vuh en donde las personas que no pertenecían a este linaje se atemorizaban al escuchar las voces emitidas por estos primeros hombres sin poderlos ver:

En cuanto a Balam Quitzé, Balam Acab, Mahucutah e Iquí Balam, no se sabía donde estaban. Pero cuando veían a las tribus que pasaban por los caminos, al instante se ponían a gritar en la cumbre de los montes, lanzando el aullido del coyote y el grito del gato de monte, e imitando el rugido del león y del tigre.

$\mathrm{Y}$ viendo las tribus estas cosas cuando caminaban: - Sus gritos son de coyote, de gato de monte, de león y de tigre, decían. Quieren aparentar que no son hombres ante todas las tribus, y sólo hacen esto para engañarnos a nosotros los pueblos. Algo desean sus corazones. Ciertamente no se espantan de lo que hacen. Algo se proponen con el rugido del león, con el rugido del tigre que lanzan cuando ven a uno o dos hombres caminando; lo que quieren es acabar con nosotros. ${ }^{12}$

Es importante mencionar que los jaguares, además de tener un

9 Ibid., p. 129.

${ }^{10}$ Ibarra y Ojeda, op. cit.

11 Álvarez del Toro, Los mamíferos de Chiapas, p. 98-102.

12 Popol Vuh, p. 127. 
amplio gradiente de vocalizaciones, que en determinado momento los haría parecerse a otros animales, durante la época de apareamiento emiten una serie de sonidos (reclamos para el sexo contrario) que se puede escuchar prácticamente durante todo el día y a grandes distancias, pero es muy difícil verlos porque permanecen ocultos en la floresta. De estas reflexiones podrímos inferir que, en efecto, estos cuatro primeros hombres del Popol Vuh actuaban como jaguares.

Es factible que en Yaxchilán, igual que sucede en la tradición escrita, el gobemante haya adquirido las características del jaguar como el gran cazador de la selva, y a nivel simbolico, posiblemente se estaría recreando un momento mítico, en donde los elementos caóticos de la sociedad se ordenan gracias a la actividad guerrera de los primeros hombres prodigiosos. Así, la lucha original entre caos y orden se recrea en las batallas sostenidas por los dignatarios de esta ciudad contra otros pueblos que, independientemente de los fines prácticos a los que estaban encaminadas, en última instancia no serían otra cosa que rituales bélicos en donde el gobemante tendría un papel primordial dentro del cosmos como el gran ordenador universal, tal y como ocurrí con los cuatro primeros hombres del Popol Vuh y sus descendientes.

En muchas representaciones de Yaxchilán, encontramos a los señores ataviados con elementos del animal, lo que evidenciaría que no sólo su conducta estuvo asociada indisolublemente al felino, sino también su poder. En diversas escenas, los soberanos portan tocados, capas, sandalias, etc., todos estos confeccionados con piel de jaguar, así como pieles enteras del animal cubriéndoles torso y extremidades, y las garras a manera de cetro. (Figs. 3 y 4 ) Este tipo de atavío no fue exclusivo ni de Yaxchilán ni del área maya. Veamos como ejemplo la descripción que hace fray Antonio de Tello, quien acompañó a Nuño de Guzmán en la conquista del Occidente de México, del cacique del pueblo de Satira en el Valle de Banderas, Jalisco:

El señor y catzique de aquel pueblo, salió con más de tres mil 


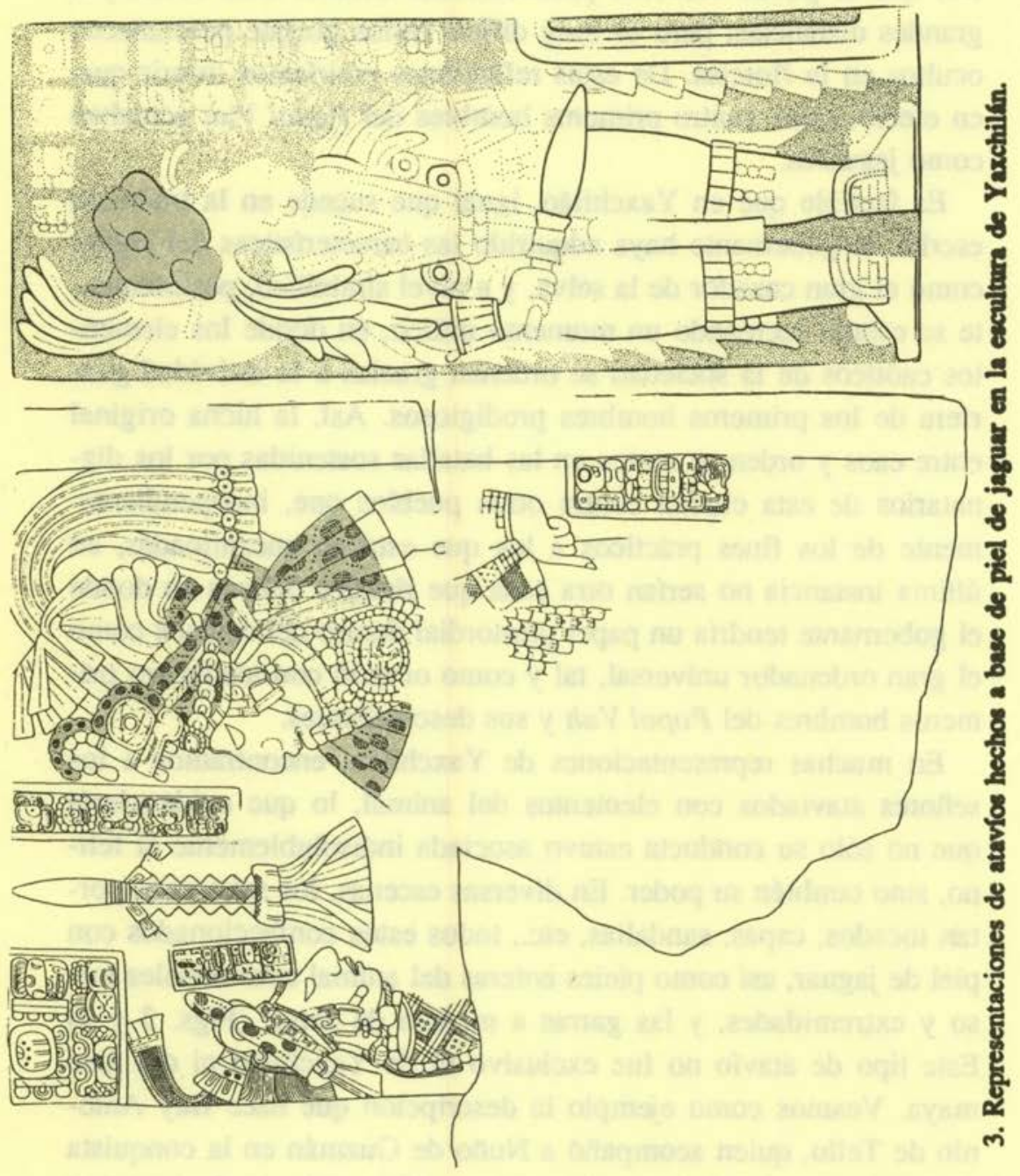




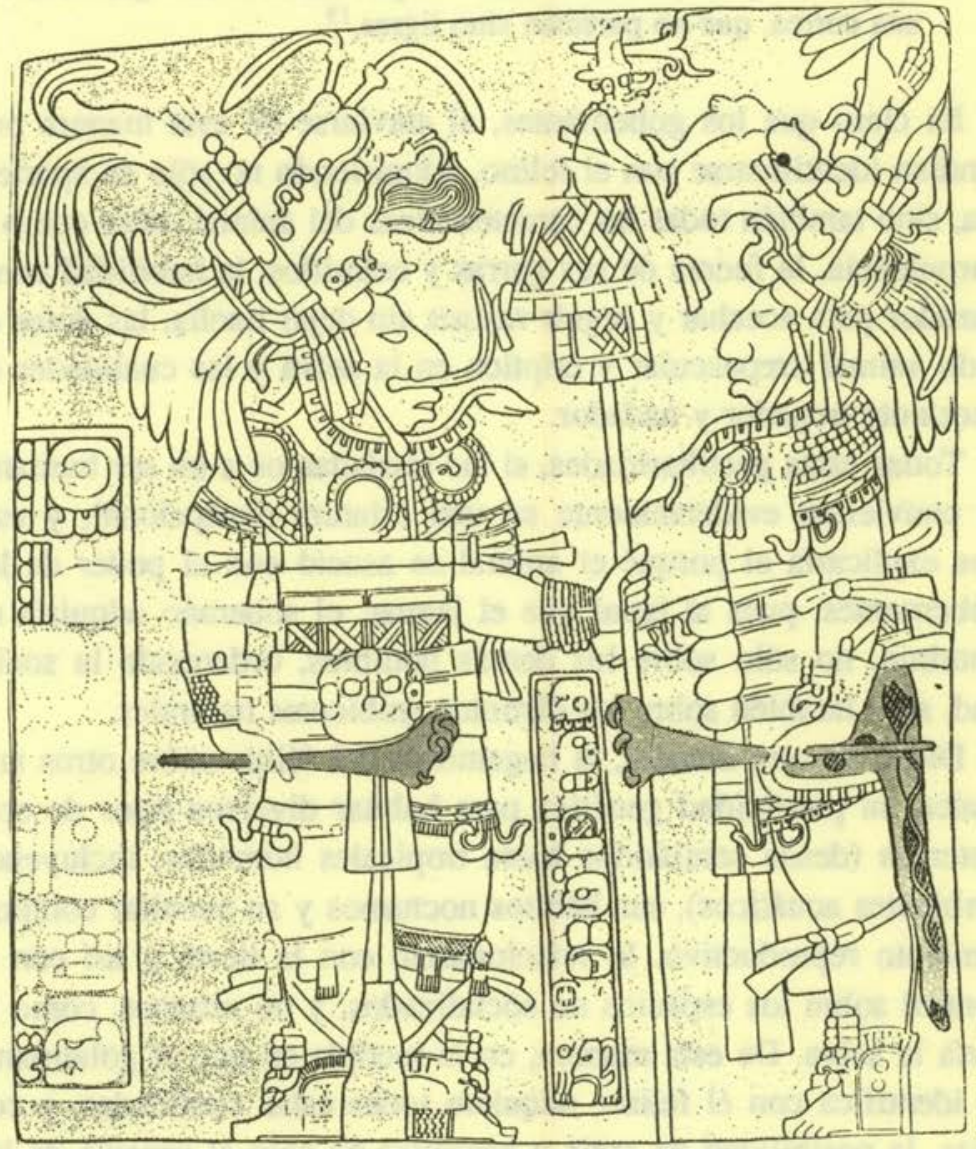

4. "Cetros" de garras de jaguar como insignia de poder. 
hombres muy galanes y con mucha plumería, con sus arcos y flechas y en las manos unos dardos de brasil muy agudos [y] tostados, que pasaron un arnes, y casi doscientos de ellos tráan por divisas y capas, queros de tigres con las cabezas del tigre desolladas y moldadas en las suyas, y sus brazos metidos en los brazos del quero del tigre, con las manoplas colgando, y desta suerte, en las piernas y la cola, arrastrando la piel hacia la barriga, asida con una correa, que no parecian sino tigres. ${ }^{13}$

Es claro que los gobemantes, al ataviarse de esta manera pretendían identificarse con el felino, adquiriendo no solo su apariencia, sino también todas las características del animal, tales como la corpulencia, la fuerza de sus garras y colmillos, la habilidad como cazador para acechar y seguir rastros sin dejar huella, las dotes de todo animal crepuscular y críptico en la selva y las cualidades de excelente trepador y nadador.

Todas estas peculiaridades, si las trasladamos a un ser humano, lo convierten evidentemente en una criatura excepcional, y esto nos explicaría el porqué el animal se asocí con el poder de los gobernantes, pues al igual que el jaguar, el soberano adquiría un dominio, no sólo sobre los demás hombres, ordenando la sociedad, sino también sobre los distintos ambientes naturales.

Dicho de otra manera, la hegemonía del félido sobre otros animales, su plasticidad genética para habitar diversos tipos de ecosistemas (desde semiáridos hasta tropicales húmedos, incluyendo ambientes acuáticos), sus hábitos nocturnos y su peculiar comportamiento reproductivo, lo relacionarian con la tierra y así con el control sobre los espacios no socializados, y no urbanos, como lo sería la selva. De esta manera, en la medida en que el gobemante se identifica con el felino, adquiere todas estas cualidades, y con ellas, la posibilidad de regir y controlar no s6lo el espacio de los hombres, que es donde vive, sino también el ámbito "salvaje" de la naturaleza. ${ }^{14}$ Sin embargo, estos dos mundos opuestos, en el

${ }^{13}$ Citado en Olguín, "Una escultura felina procedente de Huapalcalco, Hidalgo", p. 47.

${ }^{14}$ Cfr. de la Garza, "La armonía animal-hombre entre los mayas". 
pensamiento maya no permanecen aislados, se conectan y comunican a través de ritos, deidades, y sobre todo

... se armonizan en su constitución misma, ya que el ser humano contiene en su espíritu algo de la esencia del mundo natural, y la naturaleza contiene algo de la esencia humana, en los animales salvajes, que son los alter ego de los hombres. ${ }^{15}$

Sin embargo, los alter ego de los hombres van de acuerdo con el rango social del individuo. Los grandes señores, según las fuentes y algunas comunidades contemporáneas, poseen un "yo animal" más poderoso.

... parece que el yo animal evoluciona o se transforma a lo largo de la vida, de acuerdo con el ascenso en la escala social y el aumento de la edad y el prestigio del hombre, pues al mismo tiempo que se afirma que el wayjel [parte del espíritu humano que habita en un animal salvaje, según los tzotziles y los tojolabales] es el mismo desde que el hombre nace hasta que muere, un niño o un joven no tienen wayjeletik poderosos. ${ }^{16}$

El jaguar evidentemente se coloca en la cima de esta organización, que responde a su ubicación real en los ecosistemas naturales. En otras palabras, así como el felino es el "rey de la selva", el gobernante lo es de los hombres y es logico que éste quiera adquirir las características del animal para convertirse en el ser más poderoso de todos los ámbitos. De esta manera, el jaguar se convierte en el símbolo más claro de la autoridad del mandatario.

En otro orden de ideas, al parecer fue tan importante para los dignatarios mayas la idea del linaje, que en el glifo emblema de cada sitio el prefijo lo constituye una serie de pequeños círculos conocidos como "grupo acuático", y que según Coggins aludiría al semen de la estirpe gobernante. ${ }^{17}$ Esta idea se refuerza en Yaxchi-

15. Ibid., p. 31 .

16. Ibid., p. 33.

17. Coggins, "The Maniki Scepter: Emblem of Lineage", p. 136-137. 
lán no sólo en las representaciones de su glifo emblema sino también en las de las ceremonias de "la mano esparciendo", que se encuentran en las estelas en que aparecen Pajaro Jaguar III, Escudo Jaguar I, Pájaro Jaguar IV y Escudo Jaguar II (estelas 6, 18, $31,3,33,1,10,7,4)$ realizando actos onanistas, como una manera de evidenciar públicamente el linaje sagrado al que pertenecían. (Fig. 5)

El complejo simbolismo que parecen contener estas representaciones, encierra varios significados. Por una parte, tienen un obvio sentido de fertilidad, ya que el semen, al igual que la lluvia, es un agente masculino, y como potencia generadora da vida, es el que con su fuerza creadora fecunda la tierra, que es la receptora y el principio femenino. Por otro lado, estos rituales onanistas pretenden evidenciar públicamente el linaje sagrado que sólo poseen los gobernantes y que se trasmite por medio de su semen. El grupo acuático del glifo emblema de Yaxchilán, simbolizaría el poder del linaje noble que gobiema la ciudad. Para que se renueve la estirpe noble sobre la tierra, es necesario fecundarla, y esta tarea le está reservada al supremo gobernante.

Ahora bien, consideramos que este linaje es de naturaleza felina por lo que simb6licamente radica en el interior de la tierra. Las representaciones de jaguares en escenas del inframundo parecen tener este sentido, ya que este poderoso felino, como ya senalamos, comunmente se ha asociado en el pensamiento indígena con la noche y la oscuridad, y por su comportamiento sexual, se le tomó como una criatura de extraordinaria fertilidad, equiparable a la de la tierra. En ese sentido se le relacionó con el mundo subterráneo, la región inaccesible, donde se realizan los cambios sustanciales entre la vida y la muerte. Así, cuando el gobemante riega la tierra con su semen, la vida se renueva y germina el linaje noble. ${ }^{18}$

La idea del jaguar como símbolo de la tierra y del linaje se encuentra representada en otros sitios, con una imagen simb6lica

${ }^{18} \mathrm{Cfr}$. Sotelo y Valverde, "Jaguar y oceloxóchitl: Iconografía de un emblema de poder", p. 33, y Chevalier, Diccionario de los símbolos, p. 592. 


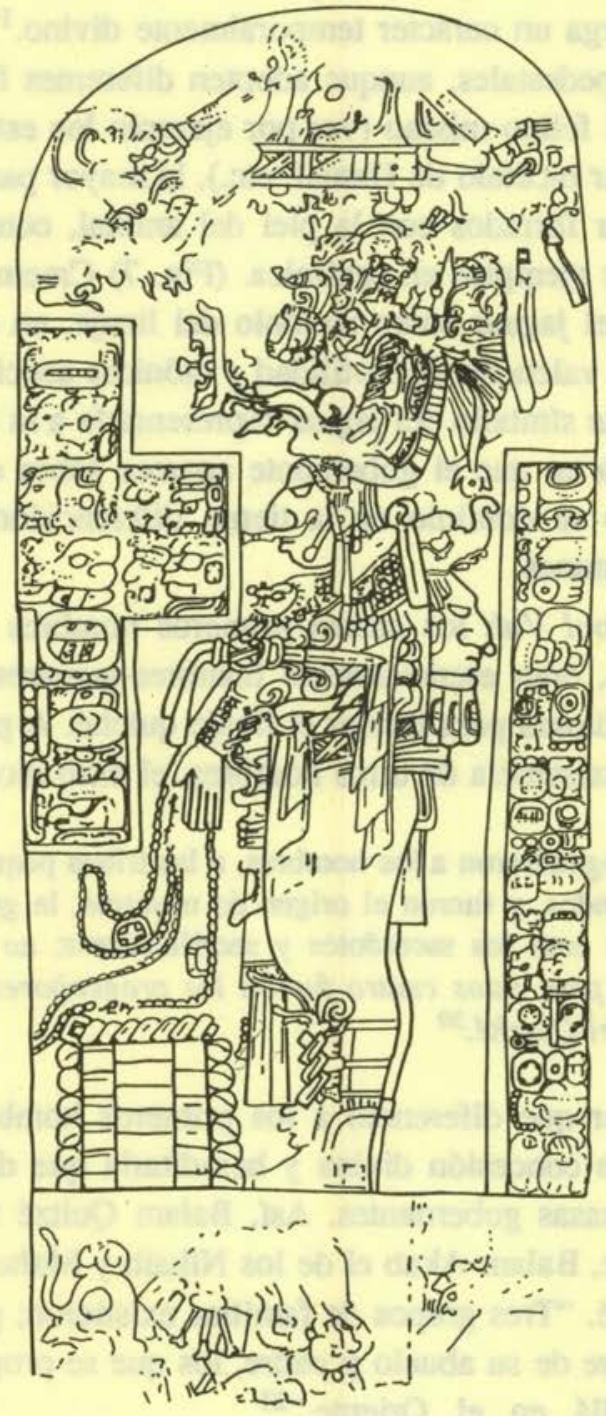

5. Estela 6 de Yaxchilán en la que aparece Pájaro Jaguar III, realizando una ceremonia de la "Mano esparciendo". Incluye una fecha correspondiente al año 669.

Estudios de Cultura Maya. Vol. XIX, 1992

Instituto de Investigaciones Filológicas/

Centro de Estudios Mayas, UNAM

ISSN 0185-2574 
paralela. Se trata de los múltiples ejemplos donde aparecen tronosjaguar. (Fig. 6) A nivel universal, el trono es la manifestación de la grandeza humana y divina, y de la armonfa cósmica; a su ocupante le otorga un carácter temporalmente divino. ${ }^{19} \mathrm{En}$ el mundo maya estos pedestales, aunque adopten diferentes formas, en ocasiones la del felino mismo (ver por ejemplo los estucos de Palenque, el jaguar bicéfalo de Uxmal, etc.), la mayor parte de las veces parecen estar forrados con la piel del animal, como lo muestran los múltiples ejemplos en cerámica. (Fig. 7) Creemos que además de la idea del jaguar como símbolo del linaje, en estos tronos se reúnen otras valencias de fertilidad y ctónicas asociadas con el félido. Asf, este símbolo del jaguar representaría a la tierra misma, y en la medida en que el gobernante aparece sobre el sitial, estarfa demostrando su dominio en la tierra, diferenciándose asi de los hombres comunes.

En el Popol Vuh los cuatro primeros hombres formados, que como vimos, eran esencialmente hombres-jaguares, fueron elegidos por los dioses para fundar el linaje quiché. A pesar de que no se niega la existencia de otros hombres, el mito dice que:

Ellos engendraron a los hombres, a las tribus pequefias y a las tribus grandes, y fueron el origen de nosotros, la gente del Quiché. Muchos eran los sacerdotes y sacrificadores; no eran solamente cuatro, pero estos cuatro fueron los progenitores de nosotros la gente del Quiché. ${ }^{20}$

Este poder que diferenció a los primeros hombres quichés de los demás es concesión divina y hereditaria que dio origen a las principales casas gobemantes. Asf, Balam Quitzé formo el linaje de los Cavec, Balam Akab el de los Nihaib y Mahucutah el de los Ahau Quiche. "Tres grupos de familias existieron; pero no olvidaron el nombre de su abuelo y padre, los que se propagaron y multiplicaron allá en el Oriente."21

19 Chevalier, op.cit., p. 1028-1030.

${ }^{20}$ Popol Vuh, p. 107. El subrayado es nuestro.

21 Ibid., p. 108. 


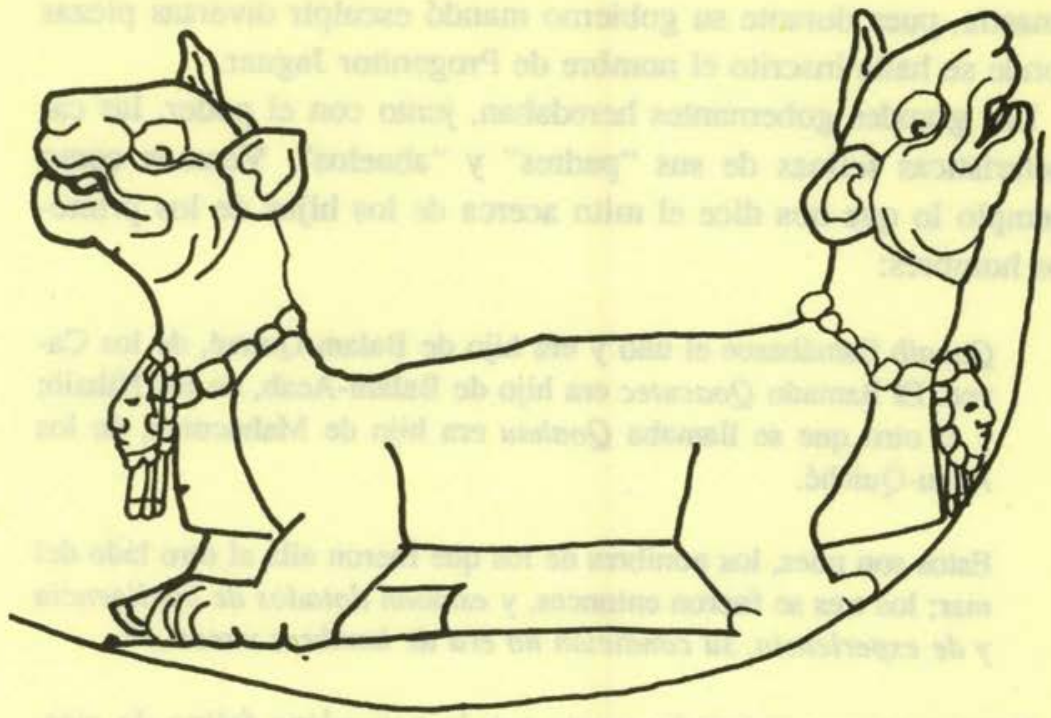

6. Lápida Oval de Palenque. Detalle que muestra un trono de jaguar bicefalo.

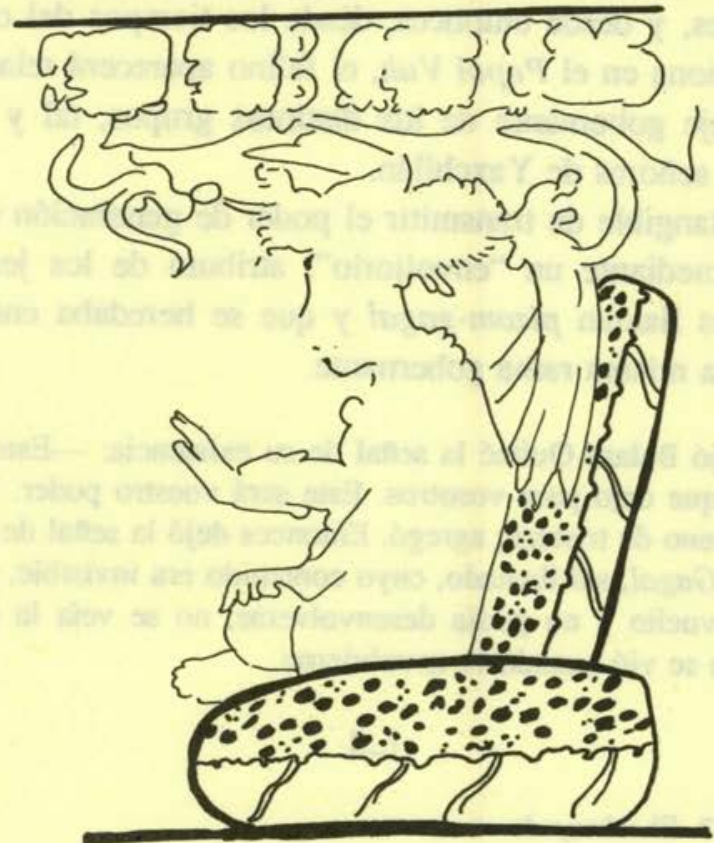

7. Representación de un trono cubierto con piel de jaguar, en un vaso de Tikal. Estructura 5D-73, entierro 196. 
De igual manera Pajaro Jaguar IV no olvida al fundador de su dinastia, pues durante su gobiemo mando esculpir diversas piezas donde se halla inscrito el nombre de Progenitor Jaguar.

Los grandes gobernantes heredaban, junto con el poder, las características felinas de sus "padres" y "abuelos". Veamos como ejemplo lo que nos dice el mito acerca de los hijos de los primeros hombres:

Qocaib llamábasee el uno y era hijo de Balam-Quitzé, de los Cavec. El llamado Qoacutec era hijo de Balam-Acab, de los Nihaib; y el otro que se llamaba Qoahau era hijo de Mahucutah, de los Ahau-Quiché.

Estos son pues, los nombres de los que fueron allá al otro lado del mar; los tres se fueron entonces, y estaban dotados de inteligencia $y$ de experiencia, su condición no era de hombres vanos... ${ }^{22}$

Pensamos que es precisamente por la naturaleza felina de ciertos hombres, por lo que fueron los elegidos para fundar las dinastías gobernantes, y desde entonces, desde los tiempos del origen, como se menciona en el Popol Vuh, el felino aparecerá relacionado con el linaje gobemante de los distintos grupos, tal y como ocurre con los señores de Yaxchilán.

La manera tangible de transmitir el poder de generación en generación fue mediante un "envoltorio", atributo de los jerarcas, que las fuentes llaman pizom-gagal y que se heredaba entre los miembros de la misma rama gobernante.

Luego dejó Balam Quitzé la señal de su existencia: -Este es un recuerdo que dejo para vosotros. Este será vuestro poder. Yo me despido lleno de tristeza, agregó. Entonces dejó la señal de su ser, el Pizom-Gagal, así llamado, cuyo contenido era invisible, porque estaba envuelto y no podía desenvolverse; no se veía la costura porque no se vió cuando lo envolvieron.

\section{$[\ldots]$}

22 Ibid., p. 142. El subrayado es nuestro. 
Se acordaban de sus padres; grande era para ellos la gloria del Envoltorio. Jamás lo desataban, sino que estaba siempre enrollado con ellos. Envoltorio de la Grandeza le llamaban cuando ensalzaron y pusieron nombre a la custodia que les dejaron sus padres como sefnal de su existencia. ${ }^{23}$

En otra parte del Popol Vuh sí se menciona el contenido del envoltorio, en el que destacan garras de leon (puma) y de tigre (jaguar); otra vez la presencia constante del felino, en este caso sus vigorosas garras símbolos de su fuerza y dominio, asociadas con la esencia misma del poder del gobernante.

El pizom gagal es conocido en las representaciones plásticas como el bulto ceremonial. En Yaxchilán este envoltorio sagrado lo portan los miembros de la dinastra, como en los casos de los dinteles $1,5,7,32,53$ y 54, donde una dama se lo está entregándo al gobernante, (Fig. 8) probablemente porque es ella la que biologicamente puede perpetuar el linaje, y en determinado momento se ve precisada a ceder al varón, además del hijo, el símbolo material que garantiza la continuidad de la dinastra.

En la figura del dintel 26, la señora "Puño Pescado" le da a Escudo Jaguar I lo que podría ser un símbolo del bulto. (Fig. 9) En este caso no se trata de un envoltorio, sino de la imagen estilizada de una cabeza de jaguar, que estaría cumpliendo la misma función que el pizom gagal, de perpetuar el poder del linaje noble. Creemos que se trata de este linaje noble de naturaleza felina, el mismo de sus antepasados que, según las inscripciones y el Popol Vuh, era hereditario.

Diversas representaciones contemporáneas a este período de Yaxchilán, sobre todo en cerámica, muestran escenas que comúnmente se conocen como "danzas del inframundo". En ellas aparece el jaguar adornado con motivos vegetales, junto con otros seres asociados también al mundo subterráneo. (Fig. 10) Tanto por las inscripciones que acompañan estas escenas, como por el elemento ahau que usualmente porta el felino adomado con estilizaciones

23 Ibid., p. 140-141. 


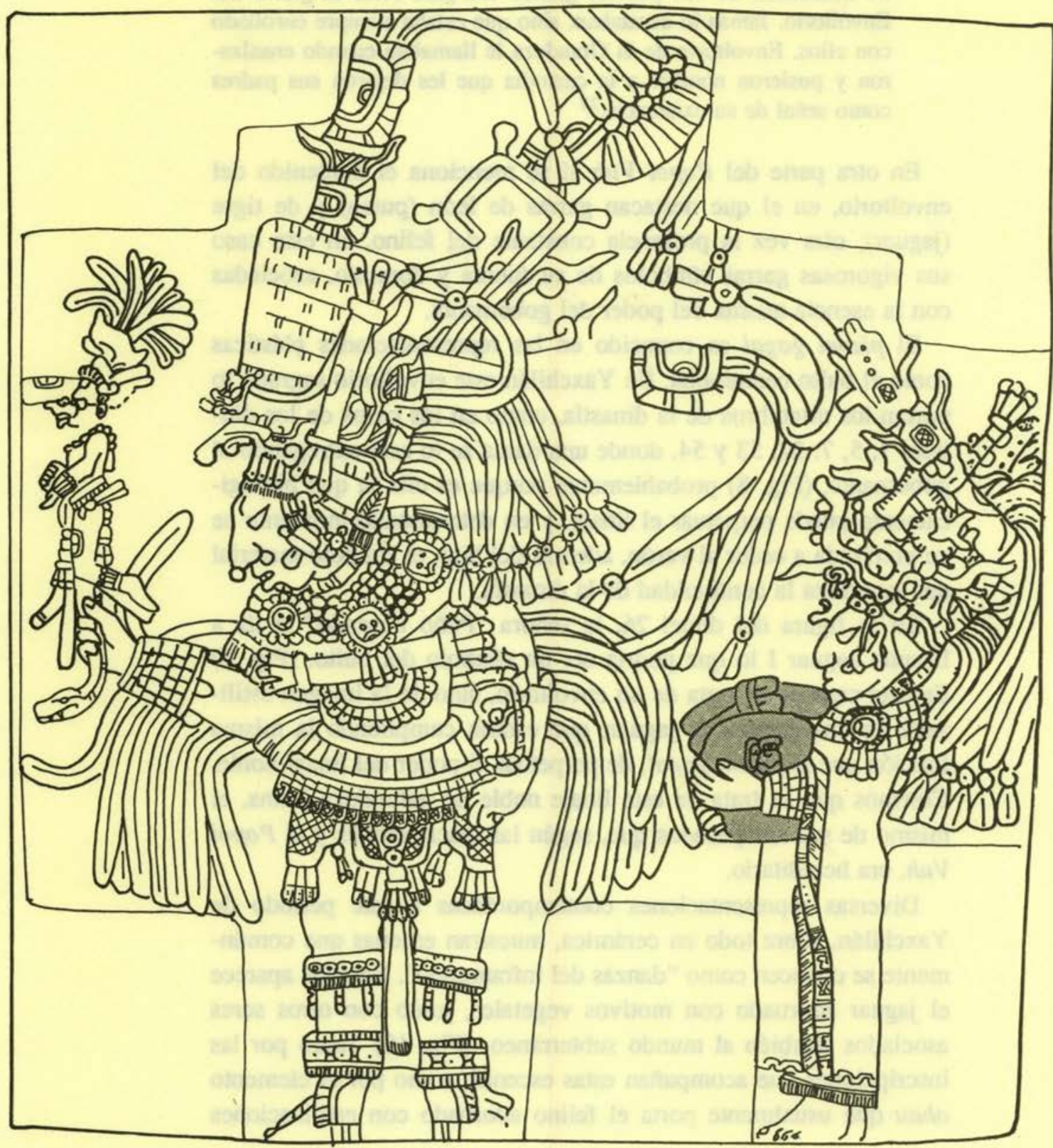

8. Dintel 1 de Yaxchilán. Representa a Pájaro Jaguar IV y a una de sus esposas, quien porta un "bulto ceremonial". El dintel incluye una fecha que corresEstuponde al laño 752 2. Vol. XIX, 1992 


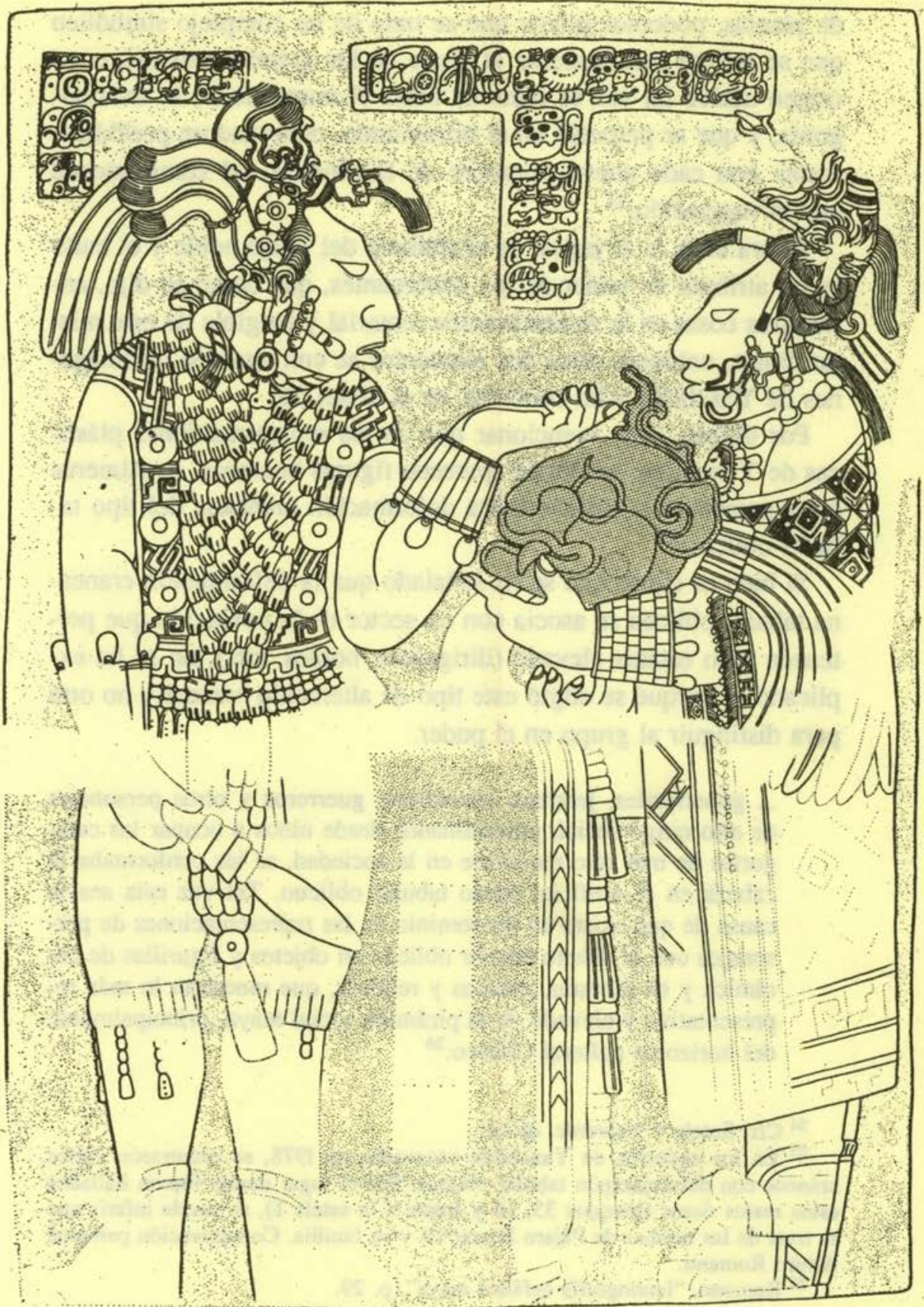

9. Dintel 26 de Yaxchilán. Representa a Escudo Jaguar I y a su esposa, la sef̂ora "Puño-Pescado", quien lleva en sus manos una cabeza estilizada de jaguar y un escudo flexible. El soberano sostiene en su mano derecha un cuchillo. La fecha inscrita corresponde al año 723.

Estudios de Cultura Maya. Vol. XIX, 1992 
de plantas, podemos inferir que se trata de un complejo simb6lico que se refiere precisamente al linaje de los grandes seffores, cuyo origen mítico tal vez se remonte hasta el momento de la antropogonía, y que se perpetúa en el inframundo, renovándose periodicamente con cada nuevo miembro de la dinastra, tal como sucede con la vegetación. ${ }^{24}$

Ahora bien, si el jaguar es el símbolo del linaje noble y el bulto es un atributo de poder de los gobernantes, que como se dijo, entre otras cosas es la representación material y tangible de este mismo linaje, entonces estos dos elementos se conjugan en las imágenes de Yaxchilán y en concreto, en el dintel 26.

Por último, cabe mencionar que en las representaciones plásticas de Yaxchilán, en donde aparecen figuras humanas, usualmente éstas presentan la característica deformación craneana del tipo tabular oblicua. ${ }^{25}$

$\mathrm{Si}$ bien es cierto que se ha señalado que la deformación craneana tabular oblicua se asocia con un sector de la población que pertenece a un estatus elevado (dirigentes, nobles, etc.), no se ha explicado el porqué se eligio este tipo de alteración crareal y no otra para distinguir al grupo en el poder.

... gobernantes, jerarcas, sacerdotes, guerreros y otros personajes de alto rango social, predestinados desde nifios a ocupar las categorías de más alto renombre en la sociedad, se les conformaba la cabeza en el artificial modo tabular oblicuo. Tal vez esta sea la causa de que exista un predominio en las representaciones de personajes con el diseño tabular oblicuo en objetos y figurillas de cerámica y en pinturas, estucos y relieves, que muestran lo más representativo y elevado de la pirámide social maya, principalmente del horizonte cultural Clásico. ${ }^{26}$

24 Cfr. Sotelo y Valverde, op.cit.

25 En los entierros de Yaxchilán excavados en 1978, se econtraron varios cráneos con deformacipón tabular oblicua. Por el lugar donde fueron hallados estos restos 6 seos (templos 33,16 y frente a la estela 1), se puede inferir que se trata de las tumbas de Pájaro Jaguar IV y su familia. Comunicación personal Arturo Romano.

${ }^{26}$ Romano, "Iconografía cefálica maya", p. 29. 


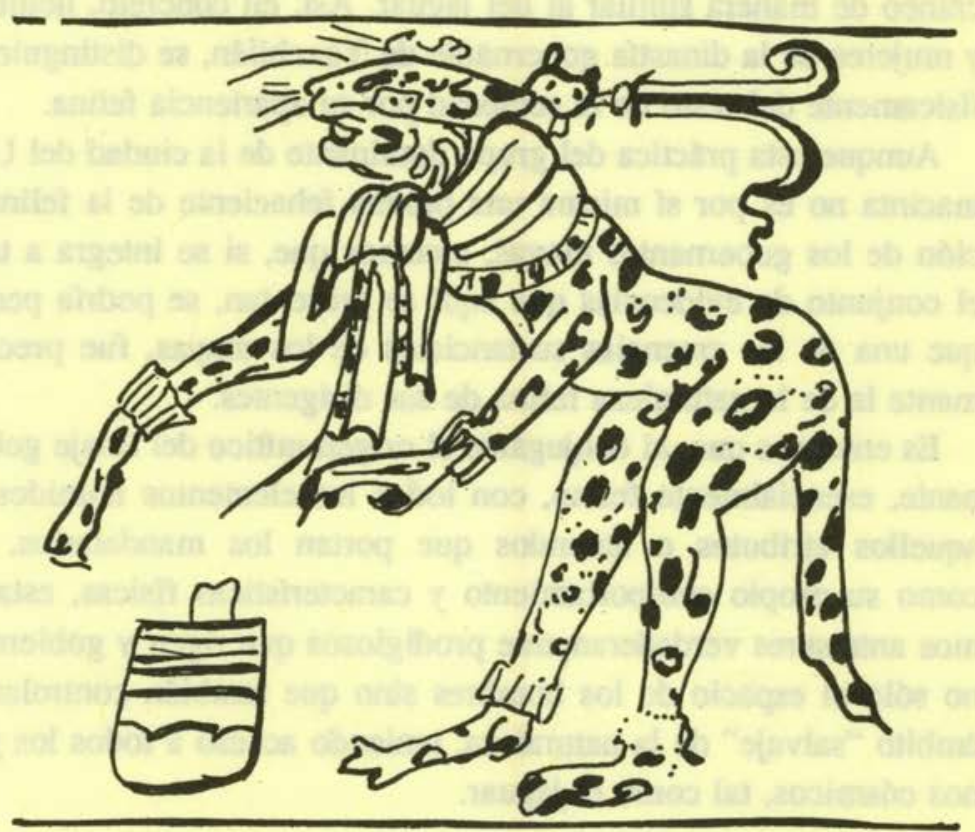

10. Vaso del Petén, colección privada. En él se muestra, entre otros personajes, a un jaguar en una escena del inframundo. 
Si comparamos un cráneo humano que presente este tipo de deformación, con el de un felino (por ejemplo el jaguar), podremos observar la gran semejanza que existe entre ambos; esto nos permite proponer que la intención que se perseguía era la de volver físicamente felino al soberano. (Fig. 11)

Es probable que al nacer los herederos, el modo más patente de evidenciar su ascendencia felina como miembros del linaje noble, fuera la de asemejarlos físicamente al animal, deformándoles el cráneo de manera similar al del jaguar. Asf, en concreto, hombres y mujeres de la dinastía gobemante de Yaxchilán, se distinguieron físicamente del resto de la sociedad por su apariencia felina.

Aunque esta práctica del grupo dominante de la ciudad del Usumacinta no es por sf misma una prueba fehaciente de la felinización de los gobernantes mayas, creemos que, si se integra a todo el conjunto de evidencias que aqui se presentan, se podrfa pensar que una de las creencias sustanciales de los mayas, fue precisamente la de la naturaleza felina de sus dirigentes.

Es entonces que, al conjugarse el origen mítico del linaje gobernante, esencialmente felino, con todos los elementos reunidos en aquellos atributos 0 atuendos que portan los mandatarios, asf como su propio comportamiento y características físicas, estarfamos ante seres verdaderamente prodigiosos que rigen y gobieman, no solo el espacio de los hombres sino que también controlan el ámbito "salvaje" de la naturaleza, teniendo acceso a todos los planos cósmicos, tal como el jaguar. 

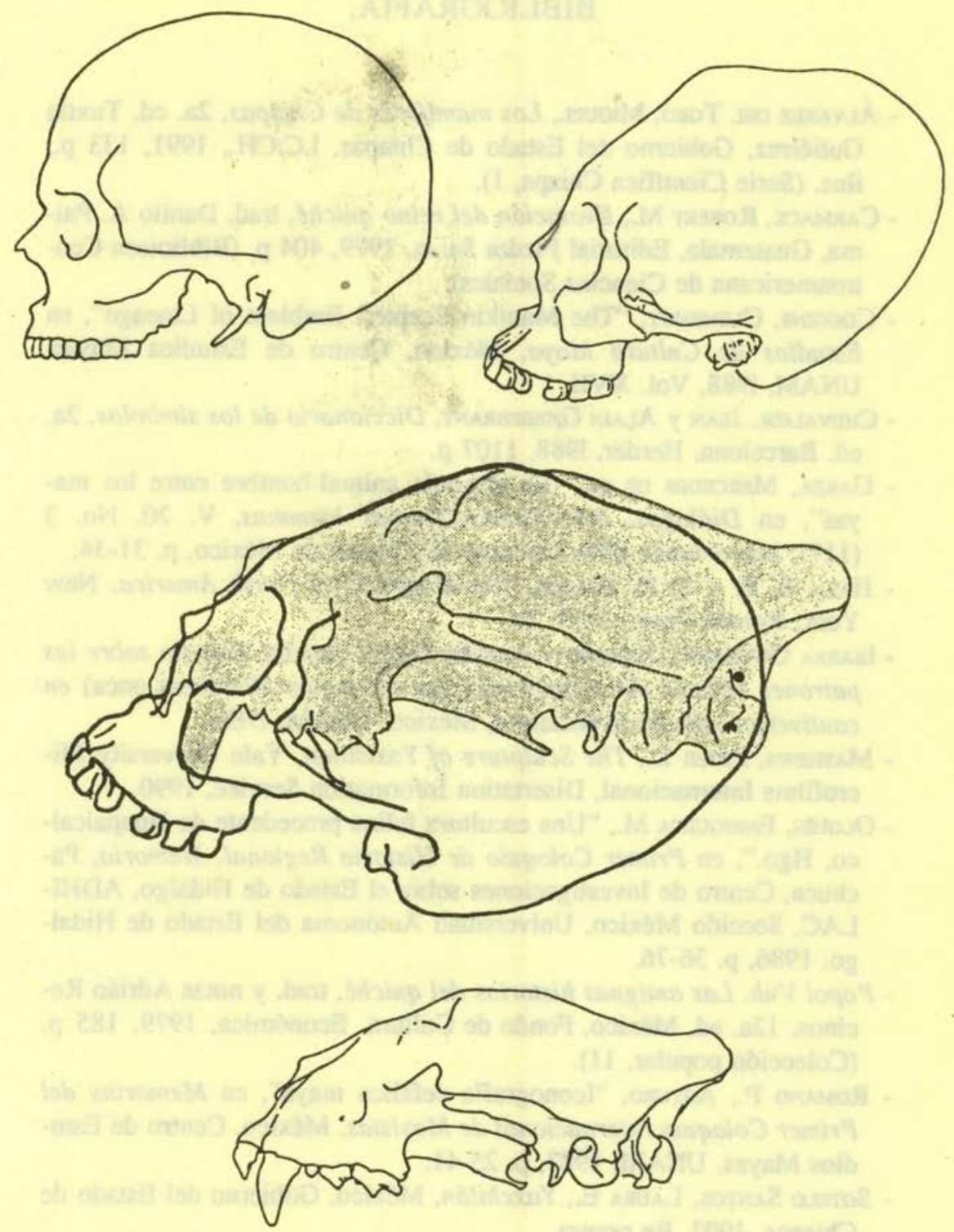

11. Cráneo humano sin deformación; cráneo humano con deformación tabular oblicua y cráneo de jaguar. 
- Álvarez del Toro, Miguel, Los mamíferos de Chiapas, 2a. ed. Tuxtla Gutiérrez, Gobierno del Estado de Chiapas, I.C.CH., 1991, 133 p., ilus. (Serie Científica Chiaps, 1).

- Carmack, Robert M., Evolución del reino quiché, trad. Danilo A. Palma, Guatemala, Editorial Piedra Santa, 1979, 404 p. (Biblioteca Centroamericana de Ciencias Sociales).

- Coggins, Clemency, "The Manikin Scepter: Emblem of Lineage", en Estudios de Cultura Maya, México, Centro de Estudios Mayas, UNAM, 1988, Vol. XVII.

- Chevalier, Jean y Alain Gheerbrant, Diccionario de los símbolos, 2a. ed. Barcelona, Herder, 1988, 1107 p.

- Garza, Mercedes de LA, "La armonía animal-hombre entre los mayas", en Diálogos. ArtesLetrasiCiencias humanas, V. 20, No. 3 (117). Mayo-Junio 1984. México, El Colegio de México, p. 31-34.

- HaLl, R. E. y R. K. Keison, The Mammals of North America, New York, Ronald Press, 1959, 2v.

- IbarRa Gutrérrez, Ricardo y Arcadio Ojeda Capella, Estudio sobre los patrones básicos del comportamiento del jaguar (Panthera onca) en cautiverio, tesis de licenciatura, México, UNAM, 1988.

- Mathews, Peter L., The Sculpture of Yaxchilan, Yale University Microfilms Internacional, Disertation Information Service, 1990.

- Olguin, ENRIQUETA M., "Una escultura felina procedente de Huapalcalco, Hgo.", en Primer Coloquio de Historia Regional. Memoria, Pachuca, Centro de Investigaciones sobre el Estado de Hidalgo, ADHILAC, Sección México, Universidad Autónoma del Estado de Hidalgo, 1986, p. 36-76.

- Popol Vuh. Las antiguas historias del quiché, trad. y notas Adrián Recinos, 12a. ed. México, Fondo de Cultura Económica, 1979, 185 p. (Colección popular, 11).

- Romano P., ARTuro, "Iconografía cefálica maya", en Memorias del Primer Coloquio Internacional de Mayistas, México, Centro de Estudios Mayas, UNAM, 1987, p. 25-41.

- Sotelo Santos, Laura E., Yaxchilán, México, Gobierno del Estado de Chiapas, 1992. En prensa.

- Sotelo, laura E. y Ma. del Carmen Valverde, "Jaguar y oceloxochi$t l$ : iconografía de un emblema de poder", en Apuntes Arqueológicos, Guatemala, Universidad de San Carlos, V. 1. No. 2, diciembre de 1991, p. 21-38. 